\title{
DeSARROLlo SOCIAL, INTEGRACIÓN Y POLÍTICAS PÚBLICAS
}

\author{
Carlos Sojo
}

\section{Introducción}

L a cuestión de "lo social" ha vuelto a ocupar centralidad en el debate más amplio sobre el enfoque que otorga preeminencia al crecimiento económico como instrumento distributivo. Cualquiera que sea el indicador observado, está claro que las opciones de crecimiento económico estimuladas en la región a lo largo de las últimas dos décadas han conducido a pobres resultados para la superación de los desequilibrios sociales más agudos. Por ello ha llegado la hora de repensar lo social. Un factor determinante que autoriza esta nueva revuelta de las ideas consiste en colocarlo en el centro y no en la periferia de la discusión sobre el desarrollo. Éste es el horizonte ético de la reflexión presente.

El artículo se estructura en tres partes. La primera intentará enfocar la discusión sobre el desarrollo social en el marco de un movimiento favorable a la comprensión holística del desarrollo. La pregunta que formulamos es si acaso tiene sentido hablar de desarrollo social cuando se ha estado insistiendo sobre la parcialidad de las definiciones que adjetivan el

Carlos Sojo, FLACso, Costa Rica. desarrollo. La respuesta que proponemos es afirmativa, no en sentido ontológico, sino respecto de la orientación de políticas públicas diferenciadas. El desarrollo es único, pero las acciones administrativas para alcanzarlo son plurales.

En el segundo apartado observaremos los límites y las posibilidades de la integración social en América Latina. La idea de integración refiere a la posibilidad de cohesión de un cuerpo social. La misma, de acuerdo con Habermas, radica en la capacidad del gobierno, por medio de normas y administración; del mercado a través de la producción y distribución de la riqueza, y del ámbito propiamente social, donde la clave no es ley o producción sino solidaridad. Estos tres ámbitos de integración muestran en la situación actual de América Latina oportunidades y carencias.

En la parte final, con pretensiones prescriptivas, reflexionamos en torno a la importancia de las variables ‘ciudadanía y territorio' en la formación de nuevos escenarios de política pública para el desarrollo social.

\section{Sobre la definición "desarrollo social": implicaciones para las políticas públicas}

Las ideas sobre el desarrollo avanzan hacia la comprensión de sus dimensiones totalizadoras, integrales 
(Sen, 1999) y no sólo de sus manifestaciones acotadas o particulares —económica, social, ambiental, etc.- Por ello en primera instancia la denominación "desarrollo social" es tan parcial e insuficiente como la del desarrollo estrictamente económico. No obstante la definición de cuestiones específicas sobre el desarrollo: social, económico, etc., es fundamental para la formulación y la orientación de políticas. En otras palabras, el desarrollo integral como aspiración ética se alcanza por medio de intervenciones especializadas sobre aspectos concretos y diferenciados.

Desarrollo social alude así a la resultante concreta de la combinación de un ámbito de de acciones, públicas y privadas, y de intervenciones institucionales, políticas, dirigidas a crear condiciones y oportunidades para que los individuos realicen sus capacidades de vivir una vida saludable, larga y digna. Lo saludable referido a la calidad de vida, asegurada por acceso a la nutrición, vivienda, educación, ambiente, cultura: la longevidad dice de la disposición de esos recursos en el largo plazo y la dignidad refiere la disposición de derechos, ciudadanos o humanos, que orientan la acción pública y la demanda social.

Que existan umbrales aceptables de desarrollo social es el producto de la interacción cooperativa de acciones productivas, distributivas, solidarias y culturales.

Las acciones productivas corresponden a los mercados, la iniciativa privada, la interacción económica en el sentido amplio. No hay condiciones para el desarrollo social en ausencia de sistemas productivos dinámicos que estimulan capacidades de bienestar humano fundamentalmente — aunque no es exclusivopor medio del empleo estable, bien remunerado, equitativo. Se sabe que el trabajo no es sólo fuente de estabilidad e ingreso material, supone también "ganancias" simbólicas asociadas al estimulo de la autoestima, el emprendimiento, el espíritu de logro.

Pero la imperfecta operación de los mercados y la necesidad de oferta de bienes y servicios colectivos, requiere de instituciones públicas activas en la distribución. La captación de impuestos, la entrega de servicios de calidad y las acciones compensatorias, sociales y económicas, a cargo del Estado son esenciales como actividades distributivas.

Las acciones solidarias refieren a intercambios de distinta índole fundamentados en propósitos altruistas. En el ámbito económico, la solidaridad comunitaria adquiere relevancia como mecanismo de potenciación de las capacidades productivas y competitivas. Capital social es aquí la palabra clave.

La cuestión cultural la asociamos a una particular visión sobre el rol de la familia. En ella se difunden valores primarios: respeto, afecto, apoyo, algunos de ellos también reproductores de los patrones que generan exclusión social: dominación patriarcal y adultocentrismo principalmente. Corresponde el ámbito donde se formulan estrategias de supervivencia y combate a la pobreza ahí donde las demás posibilidades distributivas han fallado.

\section{Desarrollo social y superación de la pobreza}

Es conveniente superar una tendencia a la confusión en las tareas del desarrollo social y las acciones más acotadas dirigidas a la superación de la pobreza. El propósito del desarrollo social es crear opciones para el desempeño de las capacidades humanas, colectivas e individuales. La consecuencia de estrategias exitosas de desarrollo social es la movilidad social ascendente. Ella se logra por medio de la disposición de mecanismos efectivos de mejoramiento de la calidad de vida que se manifiestan en cambios intra e intergeneracionales. Por ejemplo, las políticas de compensación de ingresos son instrumentos para la creación de movilidad social intrageneracional; pero las políticas de educación suelen presentar resultados a una generación de distancia. 
La superación de la pobreza es consecuencia lógica de un programa de desarrollo social donde los mecanismos de movilidad social intra e intergeneracional actúan de manera interactiva. La atención compensatoria no producirá efectos significativos en la reducción de la pobreza a menos que se articule positivamente con mecanismos de atención universal (Franco, 2002). La misma relación, articulada en el tiempo, entre iniciativas con efecto a corto plazo y las de largo aliento, alude a la recurrida pero siempre constante necesidad de distinguir entre iniciativas gubernamentales y políticas de Estado para la promoción del desarrollo. En una época caracterizada por las rigideces fiscales, resulta más atractiva para los gobiernos de turno la administración selectiva de políticas dirigidas por sus efectos en corto plazo, erosionando en ocasiones la disponibilidad de recursos para programas de corte universal y largo propósito.

El discurso racionalista electivo - perdedores y ganadores - debería eliminarse de una estrategia incluyente de desarrollo social, porque fuera de la discusión conceptual y académica la denominación "perdedor" es peyorativa. Toma en cuenta principalmente la capacidad individual, la destreza, la fuerza. En la visión schumpeteriana del capitalismo esas cualidades son propias del emprendimiento empresarial, pero en la observación de causas de pobreza e inequidad, las posibilidades individuales están mitigadas por un acceso precario a recursos institucionales que las potencien: salud, educación, tiempo libre, etc. Los perdedores son 'víctimas' de procesos de exclusión social. No obstante la denominación de las poblaciones en desventaja como "excluidos" tiende a ignorar el hecho de que la exclusión absoluta no existe, porque siempre hay mecanismos de inclusión que compensan la precariedad o la débil disposición de otros. Por ejemplo, la migración laboral es expresión de un mecanismo institucional: el mercado laboral, que excluye a una buena parte de la población laboralmente activa y al mismo tiempo proporciona recursos para la inclusión, vía remesas, de los miembros del hogar que permanecen en la comunidad de destino. La exclusión laboral es mitigada por posibilidades solidarias o culturales de integración propiciadas por las migraciones y sus efectos financieros.

En suma, la superación de la pobreza es la consecuencia de una estrategia de desarrollo social, pero no la sintetiza. Toda estrategia de desarrollo social supone programas de reducción de la pobreza, pero no todos los programas de reducción de la pobreza suponen una estrategia de desarrollo social.

Asimismo, la política económica es parte integral de una estrategia de desarrollo social. Las decisiones fiscales, monetarias y comerciales no están desprendidas de sus impactos sociales. Las exigencias de movilidad social, que materializan como hemos señalado una estrategia de desarrollo social, son inconcebibles sin programas de política económica que las activen. Sin recursos fiscales, sin crecimiento económico y sin estabilidad monetaria, el desarrollo social es impensable.

La democracia y el buen gobierno son condiciones indispensables para la promoción de estrategias de desarrollo social. La calidad de la representación política y la eficacia de la gestión gubernamental son bases principales para el levantamiento de oportunidades de movilidad social. Por ello, es preciso reconocer que toda inversión en este terreno es parte activa de una intervención en favor del desarrollo social. Y del mismo modo, es necesario poner el acento no solamente en el levantamiento y la generación de ofertas políticas institucionales, por ejemplo la celebración periódica de comicios libres y transparentes; sino de igual manera atender el resultado, el rendimiento social de su funcionamiento cotidiano.

\section{La política social como distribución}

El enfoque de desarrollo social supone una definición normativa. Está referido a la vigilancia privilegiada de 
prácticas relacionadas con la superación de la pobreza, sensibles a las diferencias dentro de la sociedad, especial pero no exclusivamente, las relacionadas con la desigualdad de género. De nuevo no se trata de menospreciar la importancia de las políticas sociales no diferenciadas de alcance universal, sino de reconocer ámbitos de urgente necesidad.

Por estas razones la propuesta derivada del enfoque de Adelantado et al., supera, a nuestro entender, las visiones unilaterales reduccionistas donde toda responsabilidad distributiva descansa o bien en el esfuerzo igualador del Estado o bien en el funcionamiento perfecto de la mano invisible del mercado. Pero incluso permite complementar las propuestas más avanzadas como la de Esping Andersen donde el reduccionismo unilateral es superado en procura de una relación tensional de complemento entre Estado, mercado y familia. El enfoque tetradimensional avanza al reconocer la importancia creciente del capital social y el entorno comunitario en la distribución de recursos para el logro de mayores umbrales del bienestar.
La dimensión estatal supone el establecimiento o en su caso la consolidación de capacidades de gestión armónicas que garanticen estabilidad en el marco normativo y en la gestión macroeconómica; calidad en la entrega de servicios y capacidad de administración; arbitraje y solución de conflictos distributivos (Grindle, 1996). Excesivo celo macroeconómico puede mitigar la calidad de la prestación de servicios. Cuando el castigo fiscal recae sobre los servicios sociales se afectan de manera sustancial la calidad de las políticas de alcance universal, educación y salud, y la posibilidad de satisfacción de las necesidades de compensación específica para sectores sociales, afectados por circunstancias coyunturales o cambios estructurales. Las inversiones sociales universales han contribuido en los países de América Latina; han sido regulares y significativas para mantener la pobreza en niveles inferiores a 30\%. En cambio, donde no existe una suficiente base de inversión social, las orientaciones selectivas y compensatorias de las políticas impulsadas en los últimos tres lustros no han permitido disminuciones sustantivas de la pobreza ahí donde los niveles superan el umbral de $50 \%$.

Figura 1

Sistema tetradimensional de distribución de recursos

\begin{tabular}{|l|l|}
\hline $\begin{array}{l}\text { EsTADO: políticas universales y } \\
\text { compensatorias }\end{array}$ & $\begin{array}{l}\text { MERCADO: mercado de trabajo e } \\
\text { ingresos. }\end{array}$ \\
\hline FAMILIA: estrategias de supervivencia. & COMUNIDAD: capital social. \\
\hline
\end{tabular}

El funcionamiento sano de los mercados, en particular del mercado laboral, es de significativa relevancia para el enfrentamiento estructural con la pobreza y sus manifestaciones múltiples. El empleo es la fuente principal del ingreso en sociedades de mercado y cuando esta condición se presenta con precariedad, el funcionamiento de la economía interna queda en entredicho. En la actualidad, siete de cada diez nuevos empleos creados en América Latina corresponden al sector informal, principalmente compuesto por ocupaciones de subsistencia, mal remuneradas e inestables.

La dimensión comunitaria debe ser incorporada plenamente como un recurso efectivo de distribución en sociedades donde lo territorial pierde centralidad 
en el plano nacional pero la gana en entornos locales, incluso de dimensiones transnacionales como ocurre en los espacios transfronterizos. En las dimensiones que hemos analizado, la intervención del Estado se refiere al fortalecimiento de la disposición de capital humano, en el sentido más general, mientras que la operación de los mercados se sustenta en flujos de inversión privada y pública que permitan la ampliación del capital físico. En el ámbito comunitario es donde se desarrolla y amplía el capital social, entendido como la acumulación de recursos productivos centrados en la solidaridad, la confianza, la comunidad de valores, entre otros rasgos de identidad comunitaria. ${ }^{1}$

En la cuarta dimensión, Familia, se desarrollan una multitud de procesos distributivos muchos delos cuales han impedido la agudización de las privaciones, en ausencia de políticas públicas, empleo estable y redes comunitarias sustantivas —especialmente en el ámbito rural-, por medio de la promoción de una variedad de estrategias de supervivencia. Además, en este escenario se empiezan a configurar los patrones culturales y las visiones de mundo que, eventualmente, en asocio con la oferta educativa van a configurar una capacidad laboral rígida y por lo tanto limitada, un oficio de calificación media o baja, o una capacidad flexible centrada en conocimientos.

Una política integral de combate a la pobreza debería buscar las interacciones entre los distintos ámbitos distributivos, aunado con una oferta de servicios sociales universales entregados en progresividad con los distintos niveles de ingreso. Todavía la región continúa invirtiendo de manera regresiva una parte importante de los recursos de inversión social. Asimismo, una política de promoción activa de los derechos sociales entre los grupos menos favorecidos deberá estimular la interacción del esquema complejo de distribución de recursos con las tres dimensiones de promoción del desarrollo social: conocimiento, salud, participación.

\section{Integración social en América Latina: ¿Cómo es que vivimos juntos?}

La región latinoamericana, aún observada en perspectivas subregionales, muestra enormes diferencias entre los países asentados, quizá tan significativas como las que se observan en las desigualdades intranacionales. La principal conclusión a la que podemos arribar es que hay 'estilos' nacionales de conducción de la política que producen rendimientos sociales diferenciados. Dicho de otro modo, aún en el medio de la impronta globalizadora que todo lo unifica en la opinión de muchos, hay todavía lugar para la política en sentido amplio y para la innovación y la adaptación antes que la simple imitación que conduce al fracaso. Sin detenernos en tales diferencias nacionales y subregionales observemos, en el agregado regional, posibilidades de integración o desintegración social. ¿Qué es lo que nos separa y lo que nos une? ¿Dónde están los desafíos para la renovación de la cohesión social en América latina?

\section{El mercado: un modelo "informal" de integración de la sociedad}

Es evidente que el mercado como institución social que regula distribución de bienes y servicios juega, en las sociedades capitalistas, un papel central en la disposición de umbrales de integración social. La tendencia en las últimas dos décadas en América Latina es que esta capacidad se encuentra en condición de estancamiento, con lo que se observan dinámicas de concentración creciente de la riqueza, mismas que acentúan la condición definitoria de nuestro subcontinente como la región más desigual del mundo.

La debilidad de los mercados proviene de su incapacidad para generar integración por medio del empleo, y por ahí podría darse la superación efectiva de la pobreza material. 
Los indicadores de la última década muestran todavía debilidad sostenida en el ritmo del crecimiento económico. Está reconocido ampliamente que los beneficios del crecimiento se acentúan en relación con su continuidad y no solamente con su magnitud. Por ello, no basta con crecer en términos reales, sino con lograrlo de manera sostenida. La volatilidad macroeconómica se ha acentuado debido a la inestabilidad de las medidas adoptadas, a la naturaleza misma de un modelo de crecimiento que estimula la gestión privada de negocios especulativos, especialmente comerciales y financieros, y que resulta además extremadamente dependiente de los acontecimientos de la economía global. Más aún, debe desenvolverse en la precariedad de nuestros regímenes institucionales, pero al mismo tiempo convive con una región donde la naturaleza 'castiga' periódicamente la falta de planificación en la formación de los asentamientos humanos y productivos.

La debilidad del crecimiento es clara. Pero la incapacidad del mismo para producir bienestar lo es más. Dos aspectos destacan: las insuficiencias del mercado laboral y la persistencia de la pobreza. De acuerdo con las cifras de CEPAL, la mayoría de los nuevos empleos de la región son generados fuera del mercado, en la llamada economía informal. Esta tendencia se ha mantenido constante durante toda la década de los noventa. Como resultado, la composición de los ocupados muestra una pérdida de dinamismo del empleo formal. Así, entre 1990 y 1999 , la proporción de empleados en el sector formal pasó de $57 \%$ a $51.6 \%$, en beneficio de las ocupaciones informales.

Adicionalmente, se observa un agravamiento en la tasa de desocupación. Entre 1990 y 1999 esa tasa se ha duplicado pasando de $4.6 \%$ a $8.6 \%$. Con ello, al finalizar el decenio, dieciocho millones de personas se encontraban sin trabajo.
El balance es precario. Una décima parte de los trabajadores capacitados no consigue empleo y la mitad de los ocupados se emplea en actividades informales, muchas de ellas por cuenta propia y capaces de poco más que la reproducción simple del trabajador y su familia, en el mejor de los casos.

La pobreza de los hogares en América latina, últimas dos décadas, se ha mantenido alrededor de $35 \%$. Sin embargo la situación en relación con el número de personas es considerablemente desfavorable: de $40.5 \%$ en 1980 a $43.8 \%$ en 1999 . Con ello la cantidad de personas en condición de pobreza pasó de 63 millones en 1980 a34 millones en 1999 . Y entre 1999 y el año 2002, aunque la proporción de población se mantiene ligeramente constante, el número de personas en condición de pobreza se habrá incrementado, de acuerdo con las proyecciones de la CEPAL, en alrededor diez millones.

El crecimiento económico precario no ha impedido, sin embargo, que los núcleos dinámicos de la sociedad experimenten ganancias sustanciales, con lo que se incrementa la desigualdad. Un balance de CEPAL lo sintetiza:

A fines de la década de 1990, la mayoría de los países de América Latina continuaron presentando un perfil de la distribución de los ingresos caracterizado por altos niveles de desigualdad. Éstos se expresan, entre otros indicadores, en la elevada proporción del ingreso total captada por $10 \%$ de los hogares de mayores recursos, que supera 19 veces la que recibe, en promedio, el 40\% de los hogares más pobres. Asimismo, entre dos tercios y tres cuartas partes de la población, según el país, perciben un ingreso per cápita inferior al promedio general.

Las razones de la desigualdad son múltiples e históricas. Estructuralmente reflejan debilidades en la captación de recursos tributarios por parte del Estado, 
A $B$ I

América Latina: población pobre (a) (b) 1980-2002

\begin{tabular}{|c|c|c|c|c|c|c|}
\hline & \multicolumn{2}{|c|}{ Total } & \multicolumn{2}{c|}{ Urbana } & \multicolumn{2}{c|}{ Rural } \\
\hline & Millones & Porcentaje & Millones & Porcentaje & Millones & Porcentaje \\
\hline 1980 & 135.9 & 40.5 & 62.9 & 29.8 & 73.0 & 59.9 \\
\hline 1990 & 200.2 & 48.3 & 121.7 & 41.4 & 78.5 & 65.4 \\
\hline 1994 & 201.5 & 45.7 & 125.9 & 38.7 & 75.6 & 65.1 \\
\hline 1997 & 203.8 & 43.5 & 125.7 & 36.5 & 78.2 & 63.0 \\
\hline 1999 & 211.4 & 43.8 & 134.2 & 37.1 & 77.2 & 63.7 \\
\hline 2000 & 206.7 & 42.1 & & & & \\
\hline 2001 & 214.3 & 43.0 & & & & \\
\hline 2002 & 221.3 & 44.0 & & & & \\
\hline
\end{tabular}

Fuente: CEPAL, sobre la base de tabulaciones especiales de las encuestas de hogares de los respectivos países. Los datos de 2000 a 2002 son proyecciones.

a/ Estimación correspondiente a 19 países de la región.

b/ Personas en hogares en situación de pobreza. Incluye a la población en situación de indigencia.

así como en la orientación progresiva de los gastos públicos. Enuncian también una limitada voluntad contributiva de las élites empresariales del continente, habituadas a la expatriación de capitales. En las últimas dos décadas, la inserción en la globalización económica ha supuesto la pérdida de dinamismo de actividades intensivas en el uso de fuerza de trabajo o que, como en el caso del empleo público, generaron condiciones de movilidad ascendente, que hoy no se reproducen en vista de las tendencias a la reducción del gasto público. En contraste, han florecido las actividades de comercio y servicios financieros, que generan menores empleos y proporcionan ingresos sobre bases competitivas globales que acentúan la distancia entre los que están insertos en la modernidad y quienes permanecen en las afueras. De ahí la importancia de la solidaridad como sistema de integración social, basado no en una normativa altruista o filantrópica, sino en el conocimiento de comunidades de intereses y su defensa.

\section{La crisis de la política}

Después de la restauración democrática en los años ochenta, que no ha sido nunca tránsito fácil, la situación en la actualidad muestra cierto grado de desmejora. Los ejemplos no son casos aislados porque en el fondo ilustran procesos comunes que solamente se diferencian en razón de la magnitud o la coyuntura. El malestar de la ciudadanía con las formas tradicionales de ejercicio del poder político no es privativo de la situación argentina, para mencionar solo un caso. Las denuncias de corrupción de altos funcionarios públicos, la incapacidad de los partidos políticos para interpretar las demandas colectivas y canalizarlas hacia decisiones políticas apropiadas; la escasez de opciones políticas diversas; la centralización excesiva de las decisiones; todos éstos son fragmentos de un diagnóstico común en la política latinoamericana. 
En muchos países de la región el final de los autoritarismos supuso un enfrentamiento bipolar con el Estado. De una parte, la sociedad desconfiaba de instituciones hasta poco tiempo antes sometidas al arbitrio del poder abiertamente dictatorial o cínicamente espurio. De la otra, intereses internos y foráneos proclives a una visión peculiar del desarrollo de los mercados requirieron el desmantelamiento de un aparato estatal considerado excesivo y dedicado a empresas que mejor desempeño habrían de presentar en manos del sector privado. No es éste el lugar considerado para analizar en detalle los alcances de ese proceso de desmantelamiento, pero en esencia ha supuesto contención del gasto, disminución de ingresos como consecuencia de las exenciones a las actividades económicas dinámicas, erosión de la inversión social y en infraestructura, especialmente grave en los países más deprimidos donde las oportunidades de creación de posibilidades distributivas han sido trasladadas a la solidaridad internacional o a la filantropía local. De especial importancia ha sido la disminución del empleo público, una base esencial de sustentación de las clases medias, expresión de los mejores logros de progreso en los pocos países de la región que experimentaron ese desarrollo. Algunos botones de muestra derivados de datos de la CEPAL: en Bolivia la proporción de asalariados del sector público respecto de la PEA ocupada urbana cayó de 18\% en 1989 a 11\% en 2000; en Costa Rica de 25\% a 19\%; en Ecuador de 17\% a $11 \%$ y aún en países donde la proporción inicial era baja continuó cayendo como en Guatemala, de 14\% en 1989 a 8\% en 1998.

La motivación esencial de la reforma del Estado y de sus consecuencias políticas es protomercantily sus mecanismos de ejecución han estado obsesivamente referidos a las posibilidades fiscales. En ese sentido la reforma impulsada no ha supuesto una revisión significativa de las funciones del Estado. El pensamiento dominante impulsó una visión de la gestión pública centrada en el logro de equilibrios macroeconómicos. Pero esa es, como señalamos arriba, solamente una de cuatro funciones esenciales de la administración pública. Se requiere además del fortalecimiento de las funciones institucionales, referidas a la formación de reglas de juego y a la garantía de su plena observancia; de las funciones administrativas asociadas a la disposición y entrega de servicios públicos de calidad y de las funciones políticas dirigidas a la capacidad efectiva para atender demandas sociales y ejercer mediación o arbitraje ante los conflictos dentro del ámbito privado.

Los gobiernos latinoamericanos han impulsado políticas en las últimas dos décadas que han conducido a una malformación del Estado. Marcada atención en los equilibrios fiscales ha penalizado la calidad de los servicios y la posibilidad de atención efectiva de las demandas de la población. Por otro lado, irresponsabilidad o mal praxis en la gestión macroeconómica, más allá de situaciones coyunturales, puede conducir a severos costos políticos y a crisis de legitimidad de difícil superación. Si la calidad de los servicios está debilitada y la posibilidad de atención a las demandas de la población reducida por insuficiencia de recursos fiscales, la capacidad política de los Estados experimenta desmedro.

Evidentemente, el mejoramiento de la integración social por vía de la administración requiere de un conjunto de medidas orientadas a generar un desarrollo armónico de las capacidades del Estado. Dos aspectos parecen pretender especial cuidado, con el fin de propiciar condiciones para una restauración de la confianza ciudadana en el Estado democrático latinoamericano. Se trata de un programa básico para el mejoramiento de la gobernabilidad de los sistemas y de una ampliación de los espacios de democracia directa ahí donde la representación delegada ha manifestado desempeño insuficiente.

La ecuación de la gobernabilidad supone la interacción de Gobierno y sociedad. La observación 
parece simple, pero se olvida con pasmosa recurrencia. Los gobiernos acusan de ingobernabilidad a la común dificultad del ejercicio del poder administrativo, en especial, cuando hay severa limitación de recursos fiscales para la distribución de demandas crecientes. Como se ha planteado desde hace una década (World Bank, 1992), la responsabilidad gubernamental es un factor esencial. Un buen gobierno supone transparencia en la gestión pública, información apropiada para la toma de decisiones y responsabilidad en el cumplimiento de los objetivos pactados con la ciudadanía y en el uso de los recursos públicos. Una rápida mirada a la situación general de los gobiernos latinoamericanos muestra deficiencias importantes en los tres sentidos. Desde la perspectiva de la sociedad, la cuestión de la gobernabilidad a menudo se asocia simplemente a la incapacidad del Estado o a la corrupción administrativa. Una parte importante de la responsabilidad corresponde a organizaciones sociales que saben agregar demandas y gestionarlas ante el Estado. La atomización y el cortoplazismo a menudo perjudican la formación de opciones políticas administrativamente viables y socialmente pertinentes.

Una respuesta a los desafíos de la gobernabilidad democrática proviene de la implantación de formas de democracia deliberativa centradas en una multitud de procesos de diálogo social. La idea del diálogo social es el complemento activo de las dimensiones representativas de la democracia que permite al mismo tiempo avanzar en la construcción de políticas públicas incluyentes y orientadas a la ampliación de la equidad social.

En síntesis, la integración social por medio de la acción del Estado está demandando mayor responsabilidad gubernamental, la capacidad para agregarse de la sociedad civil, y mayores oportunidades de encuentro activo entre los gestores político-administrativos y los actores sociales.

\section{Solidaridad y exclusión social}

La idea de exclusión social toma en cuenta los marcos institucionales dentro de los que tienen lugar procesos políticos y culturales que generan distintas formas de privación humana. La insuficiencia de ingresos para la satisfacción de las necesidades humanas es una forma de exclusión; pero no necesariamente la igualación de los ingresos al nivel establecido como mínimo requerido supone la superación de otras formas de exclusión social. La noción de exclusión permite aproximarse a la interacción de factores como la edad, el género, la etnia, el territorio, con las dimensiones materiales de la privación humana para identificar transformaciones institucionales requeridas en su superación.

La superación de la exclusión social compete a todas las formas de integración que hemos examinado, la administrativa y la de los mercados, pero esencialmente convoca la solidaridad social.

Supone la disposición de un ámbito efectivo de ejercicio de derechos civiles, políticos y sociales que permita la identificación de todo tipo de cuestiones y su elevación a procedimientos decisivos que influyan la administración y orientación de las políticas públicas tanto como en la operación de los mercados.

En América Latina, el vínculo entre las formas de exclusión social y la pobreza material es notorio. En Guatemala, la pobreza es fundamentalmente sufrida por la población de origen maya; como lo es en Perú y Bolivia. En todo el continente, la imagen de la 'feminización' de la pobreza llama la atención sobre la concentración de efectos derivados del empleo, el costo de la vida y el ciclo familiar que castigan principalmente a las mujeres. La CEPAL encuentra que la probabilidad de empobrecimiento para los hogares 'jefeados' por mujeres no es mayor a la del promedio de los hogares sostenidos por hombres, y ello parece corresponder con el hecho de que actitudes asociadas al ejercicio de 
la jefatura femenina del hogar pueden más bien constituirse en antídotos contra el empobrecimiento. La situación de las mujeres pobres en los hogares nucleares, por ejemplo, está menos estudiada y constituye quizá uno de los problemas más severos de exclusión social desde la perspectiva de género.

Los negros son tendencialmente más pobres que los blancos en Brasil. La cuestión étnica, la raza y la exclusión aparecen de forma recurrente en el escenario político y social de América Latina. La negación administrativa de la existencia de prácticas discriminatorias contrasta con la evidencia de mecanismos de obstáculo al disfrute del bienestar por parte de los grupos étnicos y raciales subordinados. Como lo plantea Trouillot (2000: 129) "Los procesos de exclusión sociocultural coexisten en la segmentación de la población en grupos que son inherentemente desventajosos debido a que sus orígenes culturalmente marcados les dan un bajo acceso al capital social y cultural. Tales marcas socioculturales pueden incluir color, etnicidad, u orígenes nacionales; idioma, o género".

En todo el continente, la proporción de adultos mayores, niños y adolescentes y mujeres entre los hogares pobres, es mayor que entre el total de los hogares. Territorialmente, los países de la región están agobiados por asimetrías de desarrollo absolutamente dramáticas que ilustran la desigualdad de las oportunidades en relación con la distancia de los centros dinámicos del poder económico y político. La pobreza rural es más intensa y extendida que la pobreza urbana. La proporción de hogares en condición de pobreza en el campo es el doble que en las ciudades y la indigencia más de tres veces superior. Los niveles de desarrollo humano, en las ciudades capitales de América Latina, no se distancian mucho de los países industriales de alto desarrollo. En cambio, las dimensiones de ese desarrollo en espacios económicos y culturalmente aislados no son muy diferentes de los agregados nacionales en el África subsahariana.

\section{Reflexiones a futuro}

Lo señalado posibilita afirmar la pertinencia de la idea de desarrollo social como ámbito especializado de intervención institucional. Esto significa que en el propósito ético del desarrollo, que no admite distinciones ni jerarquías en sus distintos componentes: político, económico, social, cultual y ambiental; las intervenciones específicas en la promoción de su forma propiamente social son pertinentes e importantes a la luz de una evidencia factual dura: su concreción automática como resultado de la operación de mercados o ámbitos político-institucionales no han producido resultados significativos.

En América Latina, los rezagos de desarrollo social se manifiestan de manera contundente en el estancamiento de los altos niveles de pobreza y la ampliación de los ya exagerados patrones de desigualdad social. En esta región, deben ser los propósitos primordiales de una estrategia de desarrollo social. En otras regiones, la urgencia de los desafíos puede ser distinta, por ejemplo en el plano de la importancia de las intervenciones primarias en salud - para alargar la vida en el África subsahariana- o la adaptación de requerimientos educacionales — para aumentar la competitividad en las democracias emergentes del campo socialista.

La atención de esos rezagos, hemos propuesto, debe acometerse repensando dos cuestiones básicas: la cuestión territorial y la problemática de las ciudadanías.

Territorialidad. El modelo de desarrollo seguido por América Latina, hasta el estallido de la crisis de los ochenta, estuvo fundado en la centralidad del Estadonación como eje fundamental. De ahí derivaron las propuestas de substitución de importaciones y fomento de los mercados internos que perfilaron la formación de marcos institucionales en la mayoría de los países de la región. Las tendencias económicas y políticas de 
la segunda modernidad, la globalización, han supuesto una redefinición de la centralidad de la Nación como espacio territorial privilegiado, dando lugar a procesos socioeconómicos claramente desprendidos de vínculos nacionales y territoriales, como a la explotación de prácticas locales de generación de dinamismo económico y social que, por ejemplo en los espacios transfronterizos, implican la fusión de fragmentos periféricos de nacionalidades diversas. De ahí la primacía de "lo local" en estrategias incluyentes de nueva generación.

Ciudadanía. Las intervenciones políticas sobre lo social han establecido una vinculación con los sujetos que conduce a la subordinación y no a la interacción positiva. El modelo asistencial dominante en el periodo anterior dio primacía a la conformación de sujetos a partir del mercado laboral, mientras que estableció relaciones paternalistas con los sectores marginados de las relaciones laborales. La comprensión de la condición sujetiva, a partir del enfoque de la ciudadanía, conocido también como el "enfoque de derechos", supone el reconocimiento de una interacción positiva entre sujetos depositarios de derechos que deben respetarse y salvaguardarse legalmente, y políticas públicas que suponen roles activos entre los beneficiarios que también son portadores de deberes. Programas como los subsidios de ingreso para asistencia escolar, tipo bolsa escolar o Progresa, procuran la garantía del derecho a la educación pero exigen su observancia por parte de las familias. El enfoque de ciudadanía en la orientación de políticas de desarrollo social debe recoger tres aspectos fundamentales: la definición de umbrales de bienestar está determinada por tensiones de carácter global y por lo tanto transnacional; la visión electoral de la ciudadanía política, democracia electoral, no es suficiente para resolver los problemas de la tensión entre los efectos de la operación de los mercados y el derecho al desarrollo social. Por último, la provisión de bienestar no es más la responsabilidad última del Estado, como promulgó el modelo desarrollista, o del mercado como pretendió la restauración neoliberal, sino de la interacción relacionada de ambos en ámbitos comunitarios y culturales específicos.

\section{Notas}

${ }^{1}$ Una síntesis de distintas aproximaciones conceptuales a la idea de capital social se encuentra en CEPAL (2002).

\section{Bibliografía}

Adelantado, José, et al., 1998, "Las Relaciones entre Estructura y Políticas Sociales: Una propuesta teórica”, Revista Mexicana de Sociología, 3/98: 123-156.

CePal, 2002, Panorama Social de América Latina y el Caribe, www.eclac.org

Esping Andersen, Gosta, 2001, "Reestructuración de la Protección Social. Nuevas estrategias de reforma en los países adelantados", en Rolando Franco (coord.), Sociología del Desarrollo, Politicas Sociales y Democracia, Editorial Siglo xxI, México.

Franco, Rolando, 2002, "Grandes temas del Desarrollo Social en América Latina y el Caribe", en Carlos Sojo (editor), Desarrollo Social en América Latina: Temas y Desafios para las políticas públicas, FLACso-Banco Mundial, San José, Costa Rica.

Gacitúa, Estanislao; Carlos Sojo y Davis, Shelton (eds.), 2001, Social Exclusion and Poverty Reduction in Latin American and the Caribbean, The World Bank- FLAcso, San José.

González de la Rocha, Mercedes y Grinspun, Alejandro, 2001, "Private Adjustments: Household, crisis and work", en Grinspun, Alejandro (ed.), Choices of the Poor. Lesson From National Poverty Strategies, UNDP, New York.

Gordon, Sara, 2002, "Desarrollo Social y Derechos de Ciudadanía”, en Carlos Sojo (editor), Desarrollo Social en América Latina: Temas y Desafíos para las políticas públicas, FLACso-Banco Mundial, San José, Costa Rica.

Grindle, Marilee, 1996, Challenging the State. Crisis and Innovation in Latin America and Africa University Press, Cambridge.

Grinspun, Alejandro (ed.), 2001, Choices of the Poor. Lesson From National Poverty Strategies, UNDP, New York. 
Habermas, Jürgen, 2001, Facticidady validez: Sobre el derecho y el Estado democrático de derecho en términos de teoría del discurso, Editorial Trotta, Madrid.

PNUD, 1999, Informe sobre el Desarrollo Humano 1999, UNDP, New York.

Sen, Amartya, 1999, Development as Freedom, Knopf, New York. Sojo, Carlos, 2000, "Dinámica Sociopolítica y Cultural de la Exclusión Social”, en Estanislao Gacitúa, Carlos Sojo y Shelton H. Davis (editores), Exclusión Social y Reducción de la Pobreza en América Latina y el Caribe, FLACSO-Banco Mundial, San José, Costa Rica.

—, 2002, "La Noción de Ciudadanía en el debate latinoamericano", Revista de la CEPAL, Núm. 76: 25-38.
-, 2003, "El fomento de los derechos sociales en las poblaciones más desfavorecidas en el contexto de sociedades pluriculturales", en Klaus Bodemer (editor), Políticas públicas, inclusión social y ciudadania, RECAL-IIK-Nueva Sociedad, Caracas, Venezuela.

Trouillot, Michel-Rolph, 2000, "Exclusión Social en el Caribe", en Estanislao Gacitúa, Carlos Sojo y Shelton H. Davis (editores), Exclusión Socialy Reducción de la Pobreza en América Latinay el Caribe, FLACSO -Banco Mundial, San José, Costa Rica.

World Bank, 1992, Governance and Development, The World Bank, Washington.

World Bank, 2000, World Development Report. 2000-2001,The World Bank, Washington, D.C. 